Frances Chung FRCPC, Charles Imarengiaye MBBS FWACS

\title{
Management of sleep apnea in adults
}

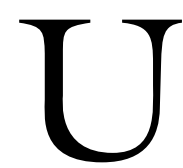

PPER airway patency is essential for normal respiratory function. The maintenance of a patent airway is dependent on the pharyngeal and laryngeal structures. However, during speech, deglutition, regurgitation and eructation, the laryngeal and epiglottis do close momentarily. This is a protective mechanism that occurs during normal respiratory activities. The morphologic structure of the upper airway is important in the maintenance of the patent airway during sleep and wakefulness. The nasal passage has a bony architecture with the cartilaginous larynx and extrathoracic trachea, which helps produce a conduit for inspiration and expiration of air during sleep and wakeful state.

However, in some individuals, there is a loss of this protective mechanism. In these individuals, obstruction to airflow does occur during sleep. The degree and extent of the obstruction and the ensuing clinical state is variable but critically dependent on the dilator muscles of the pharynx. The pharynx due to its characteristic structures remains a potential zone for the interruption of airflow. The three anatomic segments of the pharynx (nasopharynx, oropharynx, hypopharynx) have compliant structures, are liable to collapse resulting in obstruction to airflow during sleep (obstructive sleep apnea). The objective of this course therefore, is to provide a synopsis of the anesthetic management of this rather challenging clinical syndrome.

\section{Definitions}

Obstructive sleep apnea (OSA)

OSA is defined as the absence of airflow for more than ten seconds despite continuing ventilatory efforts, five or more times per hour of sleep with associated decrease in arterial oxygen saturation $\left(\mathrm{SaO}_{2}\right)$ of more than $4 \%$. Obstructive sleep hypopnea $(\mathrm{OSH})$ is defined as a decrease in airflow of more than $50 \%$ for more than ten seconds, 15 or more times per hour of sleep, and is usually associated with snoring, oxygen desaturation of greater than $4 \%{ }^{1}$

\section{Apnea hypopnea index (AHI)}

The number of abnormal respiratory events (apnea and hypopnea) per hour of sleep. Sleep apnea syndrome (SAS) is defined as recurrent apneas or hypopneas that are associated with clinical impairment as manifested by increased sleepiness or altered cardiopulmonary function. ${ }^{2}$

\section{Sleep disordered breathing}

It is a term used to indicate any degree of sleepinduced airflow limitation including snoring, hypopnea or apnea. ${ }^{3}$

\section{Epidemiology}

The earlier estimates of OSA were derived from clinical case series and reports of features suggestive of severe OSA. Epidemiologic surveys show an association between snoring, sleep apnea and cardiovascular disease. Young et al., ${ }^{4}$ in a community-based study of workers in Wisconsin estimated $2 \%$ of women and $4 \%$ of men had symptoms sufficient to meet the criteria for SAS. This prevalence is similar to other reports from some countries. Although there is a growing recognition of OSA, there is a disparity between the high prevalence of occult sleep apnea in the general population and the presumed low level of its clinical recognition. The prevalence of clinically diagnosed OSA in middle aged adults showed that at least $80 \%$ of all moderate to severe SAS is likely missed. ${ }^{5}$ The estimation of SAS in patients attending the primary care center revealed that $37.5 \%$ of patients had risk factors for SAS. ${ }^{6}$

Nevertheless, obesity, gender and age are the well documented epidemiological factors associated with OSA. Obesity, defined as body mass index (BMI) greater than $28 \mathrm{~kg} \cdot \mathrm{m}^{2}$, is present in $60-90 \%$ of OSA patients evaluated in sleep clinics. ${ }^{7-10}$ The site of fat distribution further modifies the correlation between OSA and obesity. Central obesity particularly involving the neck is predictive of those with greatest risk of OSA. ${ }^{9}, 11$ The obesity is thought to affect the airway

\footnotetext{
From the Department of Anesthesia, Toronto Western Hospital, University Health Network, University of Toronto, Toronto, Ontario, Canada. Address correspondence to: Dr. Frances Chung, Department of Anesthesia, Toronto Western Hospital, University Health Network, 399 Bathurst Street, EC 2-046, Toronto, Ontario M5T 2S8, Canada. Phone: 416-603-5118; Fax: 416-603-6494;

E-mail: frances.chung@uhn.on.ca
} 
size through deposition of fat in the neck or external compression. ${ }^{12}$ In one study, the effect of obesity was estimated to be fourfold stronger than the influence of age and twice as strong as the influence of gender in predicting breathing disorders in the elderly. ${ }^{13}$

OSA is a disorder with male preponderance. The male:female ratio ranges between $2-3: 1$ in the general population compared to the 10:1 to 90:1 ratios from clinic based studies. ${ }^{14}$ In the general population samples, there is a body of evidence that sleep apnea occurs more frequently than assumed in women. ${ }^{4,15,16}$ The male gender further modifies other significant associated factors like obesity. Females with OSA have higher BMI than males to manifest similar severity of symptoms. ${ }^{17}$ The difference in the prevalence of OSA between males and females is not clear. Sex hormones especially androgens are thought to modulate the development of OSA. There are several reports of exogenous androgens in either men or women precipitating OSA in individuals without previous history of sleep disordered breathing. ${ }^{18,19}$ Furthermore, Fogel et $a l^{20}$ showed an increased prevalence of OSA in obese women with polycystic ovary syndrome; a disorder characterized by excess androgens. The evidence from gender differences in anatomy, pharyngeal dilator muscle and ventilatory control mechanism is not conclusive. However, polysomnographic findings have shown specifically that women have lower apneahypopnea index scores than men during non-rapid eye movement (NREM) sleep but similar scores during REM sleep. ${ }^{21,22}$ This suggests that whatever protects the women from upper airway collapse during NREM disappears in REM sleep. In REM sleep, muscle tone is abolished but the current evidence in tissue characteristics cannot explain this observation.

Sleep apnea is prevalent with increasing age. It is more common in the fifth through seventh decade of life. The increased incidence in the elderly may be related to the presence of other comorbidities. Young age seems to be protective against OSA by preventing airway collapse..$^{21}$

\section{Normal sleep}

In a typical night of sleep, an adult first enters nREM sleep (stages 1 and 2 ) and subsequently spends 70-100 $\mathrm{min}$ in the deep sleep (stages 3 and 4). Then follows a period characterized by generalized loss of muscle tone and rapid, roving movements of the eyes (REM sleep). This cycle is repeated at intervals of 90 min throughout the night. Thus, there are four to six cycles of REM periods per night. Basically, each cycle includes both a quiet and restorative (NREM) sleep and an active (REM) sleep.

\section{Upper airway function in wakefulness and sleep}

The almost continuous patency of the upper airway during wakefulness and sleep under normal conditions is attributable to the morphology of the upper airway. The nasal passage is a non-collapsible conduit due to its cartilaginous and bony architecture. Similarly, the larynx and extrathoracic trachea have cartilagenous framework. However, the pharynx lacks a strong structural support, and thus potentially collapsible. The stability of the pharynx and by implication the upper airway is significantly dependent on the action of the pharyngeal muscles, which are normally activated in rhythmical fashion during inspiration. ${ }^{23}$ In normal respiration, the contraction of the diaphragm and intercostal muscles against the high resistance by the nose creates a subatmospheric pressure. The airway may become collapsible when the force produced by these muscles for a given cross-sectional area of the pharynx is exceeded by the negative pressure during inspiration. ${ }^{23}$ However, in the awake subject, there is a phasic inspiratory activation of upper airway muscles slightly before diaphragmatic contraction, splinting upper airway sufficiently to prevent its collapse. ${ }^{24}$

The pharyngeal apperture and the collapsibility of the upper airway are determined by the position of the soft palate, tongue and hyoid arch. ${ }^{23,25}$ There is no single muscle implicated in the maintenance of the pharyngeal apperture. The genioglossus, tensor palatini and the hyoid muscles play major roles in maintaining a patent airway. The genioglossus pulls the tongue forward and opposes pharyngeal collapse due to the inspiratory negative airway pressure. ${ }^{26}$ The geniohyoid, sternohyoid and thyrohyoid muscles enlarge and stabilize the pharyngeal lumen by causing a forward movement of the hyoid bone. The tensor palatini retracts the palate from the posterior pharyngeal wall. The net effect of the activities of these muscles is a stable and patent pharynx, the potential collapsible segment of the upper airway.

However, the onset of sleep disturbs the functions of these muscles. Upper airway resistance has been repetitively shown to increase during sleep in normal subjects ${ }^{27,28}$ which may be twice as in wakefulness. ${ }^{27}$ Also during sleep, there is a reduction in the cross-sectional area of the pharynx. A fall in the activity of the dilator muscles of the pharynx has been proposed as the most likely mechanism for the sleep induced decrease in pharyngeal patency. ${ }^{23,27,28}$ Specifically, tonic activity of the tensor palatini decreases during sleep and correlates with upper airway resistance during sleep. ${ }^{29,30}$ The tensor palatini retracts the posterior pharyngeal wall, thus maintaining pharyngeal patency during nasal breathing, the primary route during 
sleep. ${ }^{31}$ The impaired activities of the dilator muscles result in ineffective splinting of the upper airway, thus increasing the transmission of the subatmospheric intrathoracic pressure into the upper airway. ${ }^{32}$ The interplay of the impaired upper airway muscle activity, the unopposed subatmospheric inspiratory pressure due to the elevated upper airway resistance provide a favourable ground for airway collapse during sleep.

The peculiar characteristics of the patients with OSA create a setting for airway obstruction during sleep. The development of upper airway obstruction during sleep in patients with OSA is a result of the interaction between factors such as the structural abnormality of the pharynx, the increased collapsibility of the upper airways ${ }^{33}$ and the defective airway reflexes. Obesity, one of the most associated factors with OSA, has an inverse relationship with the pharyngeal cross-sectional area. ${ }^{34,35}$ The deposition of fat predominantly in the lateral walls of the pharynx results in decreased patency of the pharynx. This increases the risk of collapse particularly during sleep, when there is relaxation of the pharyngeal dilator muscles. Similarly, increased intraluminal pressure due to superficially located fat masses, further worsens the delicate balance between transmural pressure and the compliance of the pharyngeal wall. The neck circumference has been shown to be predictive of the risk of development of OSA. ${ }^{9,11}$

Differences in the airway mechanics between individuals with OSA and others without the disorder during wakefulness may become more evident during sleep. Craniofacial bony structural abnormality has been speculated to play some role in the pathogenesis of $\mathrm{OSA}^{36}$ especially in the non-obese population. ${ }^{37}$ The consequences of the craniofacial abnormality include decreased pharyngeal cross-sectional area.

There seems to be a major role for the upper airway reflex mechanism in the maintenance of pharyngeal patency. The significance of these reflexes is demonstrated by pharyngeal airway closure on abolition of upper airway reflexes by topical anesthesia. ${ }^{38}$ These reflexes are thought to be abnormal in OSA patients. ${ }^{39}$ Defective upper airway reflexes may be a primary contributory factor to the development of OSA.

The pathophysiology of OSA is complex. Several factors ranging from abnormal anatomy, increased collapsibility of the upper airway to defective airway reflexes interact to produce the clinical state, OSA. All the factors may not be present in one particular patient. Furthermore, the predominant factor is likely to vary from patient to patient. However, the pathophysiologic sequence of events during obstructive apnea is likely to have a similar pathway as shown in

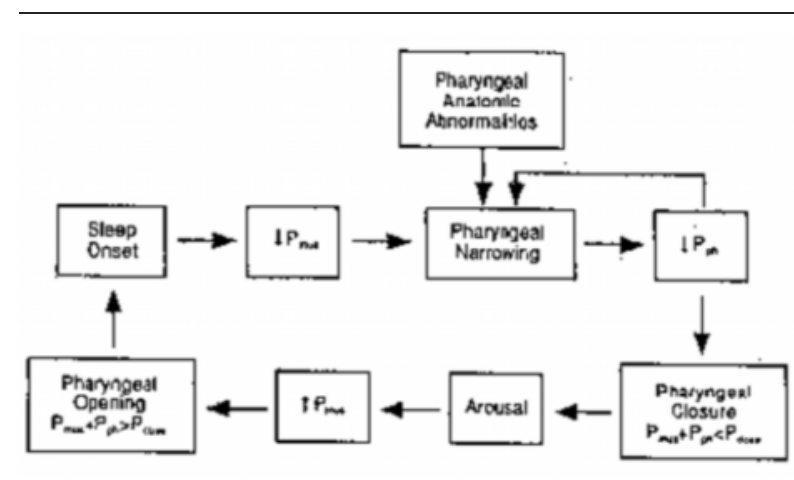

FIGURE Schematic diagram of pathophysiologic sequence of upper airway occlusions during sleep. $\mathrm{Pph}=$ pharyngeal pressure; Pmus = force arising from airway muscle activation; Pclose $=$ closing pressures. Reproduced with permission from: Remmers JE. Anatomy and physiology of upper airway obstruction. In: Kryger $\mathrm{MH}$, Roth T, Dement WC (Eds.). Principles and Practice of Sleep Medicine. WB Saunders Co, Philidelphia PA: 1989: 525-36.

the Figure..$^{40}$ Decreased upper airway muscle activity with sleep leads to pharyngeal narrowing. The ensuing rise in upper airway resistance increases transmission of the inspiratory negative intrathoracic pressure. This results in airway obstruction. Hypercapnia and hypoxia leads to arousal and pharyngeal opening due to increase in upper airway muscle activity. The improved airflow decreases carbon dioxide tension and better oxygen saturation. The cycle repeats with sleep onset.

\section{Anesthetic management of the patient with OSA}

Besides the conservative management of patients with OSA, surgical options are assuming significance. This has implications for the anesthetic management of these patients. The challenges may vary between patients for OSA related surgical procedures and those scheduled for other surgical treatment in the patient who has OSA.

\section{OSA patients for non-OSA surgery}

This category of patients consists of a mixed population of those with established diagnosis, suspected or undiagnosed cases. These patients could be scheduled for any type of surgery with varying invasiveness. All diagnosed cases of OSA should be seen preoperatively in the Anesthesia Consult Clinic. This allows for further evaluation and formulation of patient specific management goals. Generally, preoperative evaluation should include questions to identify suspected or undiagnosed population. It is clear that OSA is an underdiagnosed clinical syndrome. ${ }^{5}$ Patients should be evaluated for symptoms 
like heavy snoring, witnessed apnea by bed partner, excessive daytime somnolence and non-restorative sleep. The presence of epidemiological risk factors like obesity, male gender, advanced age and craniofacial abnormality make a thorough evaluation for OSA imperative. A history of previous difficult airway management or anticipated difficult airway should elicit suspicion of OSA. ${ }^{41,42}$ Patients already on treatment with nasal continuous positive airway pressure should be encouraged to bring the device to the operating room. The anesthesiologist should seek understanding of the specific patient's device. This may prove useful if the patient suffers airway obstruction in the immediate postoperative period. It may be prudent to avoid sedative premedicants.

The choice of anesthetic technique sways in favour of regional anesthesia (RA) when possible. RA enables the patient to retain conscious control of respiratory function. However, airway obstruction has been reported in patients with OSA following RA. The presence of central factors in OSA may be responsible for this observation. A combined regional/general anesthetic technique has also been suggested. ${ }^{3}$ The RA may be useful in postoperative management. Nevertheless, if general anesthesia is the only option, controlled ventilation with endotracheal intubation should be the choice. Difficult airway management should be anticipated and relevant airway equipment prepared. Awake tracheal intubation using the fibreoptic bronchoscope or induction with inhalation agent may be necessary. ${ }^{43}$ Inhalation agents and other drugs that will ensure prompt recovery of consciousness and upper airway integrity at the conclusion of surgery should be administered. Remifentanil infusion with multimodal, balanced analgesia may meet the intraoperative analgesic requirement for these patients.

Opinion differs on the appropriate site for postoperative care for these patients. Intensive care unit (ICU) admission seems ideal for severe OSA. However, optimal vigilance is desired for all OSA patients irrespective of severity and site of care. Certain surgical interventions like upper abdominal or thoracic procedures are notorious for severe postoperative pain and probable compromise of ventilatory function. ${ }^{44,45}$ The use of RA and non-steroidal antiinflammatory drugs may obviate the need for opioids.

\section{OSA patients for OSA-related surgery}

Uvulopalatopharyngoplasty is currently the most frequent surgical procedure for the treatment of OSA. Other site specific upper airway surgical procedures for the treatment of OSA include lingual surgery, mandibular and maxillary surgery. Common to these procedures is upper airway surgery with the risk of air- way edema. This may worsen or precipitate obstruction. ${ }^{46,47}$ It may be prudent to seek features of airway edema prior to tracheal extubation. The cuff leak test may be performed to ascertain a patent upper airway. Alternatively, the tube should be left in situ until there is reassuring evidence that the airway will not be compromised on extubation. ${ }^{48}$ There is no doubt that patients with severe OSA warranting surgical intervention should be managed further in the ICU postoperatively. ${ }^{49}$

\section{Conclusion}

Sleep disordered breathing is increasingly being recognized in the surgical population. This morbidity modifies the anesthetic care of affected patients. It is therefore imperative for the anesthesiologist to demonstrate a firm understanding of the patients at risk and the pathogenesis of this disorder. This will enable the anesthesiologist to provide specific care in the perioperative period.

\section{References}

1 Strollo PJ, Rogers RM. Obstructive sleep apnea. N Engl J Med 1996; 334: 99-104.

2 Anonymous. Indications and standards for use of nasal continuous positive pressure (CPAP) in sleep apnea syndrome. American Thoracic Society. Official statement adopted March 1944. Am J Respir Crit Care Med 1994; 150: 1738-45.

3 Boushra NN. Anaesthetic management of patients with sleep apnea syndrome. Can J Anaesth 1996; 43: 599-616.

4 Young T, Palta M, Dempsey J, Skatrud J, Weber S, Badr $S$. The occurrence of sleep-disordered breathing among middle-aged adults. N Engl J Med 1993; 328: 1230-5.

5 Young T, Evans L, Finn L, Palta M. Estimation of the clinically diagnosed proportion of sleep apnea syndrome in middle aged men and women. Sleep 1997; 20: 705-6.

6 Netzer NC, Stoohs RA, Netzer CM, Clark K, Strobl KP. Using the Berlin Questionnaire to identify patients at risk for the sleep apnea syndrome. Ann Intern Med 1999; 131: 485-91.

7 Levinson PD, McGarvey ST, Carlisle CC, Eveloff SE, Herbert PN, Millman RP. Adiposity and cardiovascular risk factors for in men with obstructive sleep apnea. Chest 1993; 103: 1336-42.

8 Davies RJO, Stradling J. The relationship between neck circumference, radiographic pharyngeal anatomy and the obstructive sleep apnea syndrome. Eur Resp J 1990; 3: 509-14.

9 Dealberto MJ, Ferber C, Garma L, Lemoine P, Alperovich $A$. Factors related to sleep apnea syndrome 
in sleep clinic patients. Chest 1994; 105: 1753-8.

10 Rajala R, Partinen M, Sane T, Pelkonen R, Huikuri K, Seppalainen AM. Obstructive sleep apnea syndrome in morbidly obese patients. J Intern Med 1991; 230: 125-9.

11 Stradling JR, Crosby JH. Predictors and prevalence of obstructive apnea and snoring in 1001 middle aged men. Thorax 1991; 46: 84-90.

12 Mortimore IL, Marshall I, Wraith PK, Sellar RJ, Douglas NJ. Neck and total body fat deposition in obese and non-obese patients with sleep apnea compared with that in control subjects. Am J Respir Crit Care Med 1998; 157: 280-3.

13 Bliwise DL, Feldman DE, Bliwise NG, et al. Risk factors for sleep disordered breathing in heterogenous geriatric population. J Am Geriatr Soc 1987; 13: 845-50.

14 Strohl KP, Redline S. Recognition of obstructive sleep apnea. Am J Respir Crit Care Med 1996; 154: 279-8.

15 Redline S, Kump K, Tishler PV, Browner I, Ferrette V. Gender differences in sleep disordered breathing in a community-based sample. Am J Respir Crit Care Med 1994; 149: 722-6.

16 Marin JM, Gascon JM, Carrizo S, Gispert J. Prevalence of sleep apnea syndrome inn the Spanish adult population. Int J Epidemiol 1997; 26: 381-6.

17 Walker RP, Durazo-Arvizu R, Wachter B, Gopalsami C. Preoperative differences between male and female patients with sleep apnea. Laryngoscope 2001; 111 : 1501-5.

18 Dexter DD, Dovre EJ. Obstructive sleep apnea due to endogenous testosterone production in a woman. Mayo Clin Proc 1998; 73: 246-8.

19 Cistulli PA, Grunstein RR, Sullivan CE. Am J Resp Crit Care Med 1994; 149: 530-2.

20 Fogel RB, Malhotra A, Pittman SD, Dunaif A, White $D P$. Increased prevalence of obstructive sleep apnea syndrome in obese women with polycystic ovary syndrome. J Clin Endocrinol Metab 2001; 86: 1175-80.

21 Ware JC, McBrayer RH, Scott JA. Influence of sex and age on duration and frequency of sleep apnea events. Sleep 2000; 23: 165-70.

22 O'Connor C, Thornley S, Hanly P. Gender differences in the polysomnagraphic features of obstructive sleep apnea. Am J Crit Care Med 2000; 161: 1465-72.

23 Remmers JE, DeGroot WJ, Sawerland EK, Anch AM. Pathogenesis of upper airway occlusion during sleep. J Appl Physiol 1978; 44: 931-8.

24 Strobl KP, Hensley MJ, Hallet M, Saunders NA, Ingram $R H$. Activation of upper airway muscles before onset of inspiration in normal humans. J Appl P 1980; 49: 638-42.

25 Hoffstein V, Zamel $N$. Sleep apnea and the upper airway. Br J Anaesth 1990; 65: 139-50.
26 Issa FG, Edwards P, Szeto E, Lauff D, Sullivan C. Genioglossus and breathing responses to airway occlusion: effect of sleep and route of occlusion J Appl Physiol 1988; 64: 543-9.

27 Hudgel DW, Martin RJ, Johnson B, Hill P. Mechanics of the respiratory system and breathing pattern during sleep in normal humans. J Appl Physiol 1984; 56: 133-7.

28 Wiegand LC. Genioglossus muscle activity in normal men during wakefulness and sleep. J Appl Physiol 1990; 69: 1262-9.

29 Tangel DJ, Mezzanotte WS, White DP. Influence of sleep on tensor palatini EMG and upper airway resistance in normal men. J Appl Physiol 1991; 70: 2574-81.

30 Tangel DJ, Mezzanotte WS, Sandberg EJ, White DP. Influences of NREM sleep on the activity of tonic vs. inspiratory phasic muscles in normal men. J Appl Physiol 1992; 73: 1058-66.

31 Gleeson K, Zwillich CW, Braier K, White DP. Breathing route during sleep. Am Rev Respir Dis 1986; 134: 115-20.

32 Kuna ST, Sant'Ambragio G. Pathophysiology of upper airway closure during sleep. JAMA 1991; 266: 1384-9.

33 Issa FG, Sullivan CE. Upper airway closing pressures in obstructive sleep apnea. J Appl Physiol 1984; 57: 520-7.

34 White DP, Lombard RM, Cadieux RJ, Zwillich CW. Pharyngeal resistance in normal humans: influence of gender, age and obesity. J Appl Physiol 1985; 58: 365-71.

35 Brown IG, Zamel N, Hoffstein V. Pharyngeal cross-sectional area in normal men and women. J Appl Physiol 1986; 61: 890-5.

36 Sakakibura H, Tong M, Matsushita K, Hirata M, Konishi $\Upsilon$, Suetsugu S. Cephalometric abnormalities in non-obese and obese patients with obstructive sleep apnea. Eur J Resp 1999; 13: 154-62.

37 Cistulli PA, Goptsopoulos H, Sullivan CE. Relationship between craniofacial abnormalities and sleep disordered breathing in Marfan's syndrome. Chest 2001; 120: 1455-60.

38 McNicholas WT, Coffey M, McDonnell, O'Regan R, Fitzgerald $M X$. Upper airway obstruction during sleep in normal subjects after selective topical oropharyngeal anesthesia. Am Rev Respir Dis 1987; 135: 1316-19.

39 Deegan PC, McNicholas WT. Pathophysiology of obstructive sleep apnea. Eur Respir J 1995; 8: 1161-78.

40 Remmers JE. Anatomy and physiology of upper airway obstruction. In: Kryger MH, Roth T, Dement WC, (Eds.). Principle and Practice of Sleep Medicine. Philadelphia PA: WB Saunders Co, 1989: 525-36. 
41 Hiremath AS, Hillman DR, James AL, Noffsinger WJ, Platt PR, Singer SL. Relationship between difficult tracheal intubation and obstructive sleep apnea. $\mathrm{Br} \mathrm{J}$ Anaesth 1998; 80: 606-11.

42 Benumof JL. Obstructive sleep apnea in the adult obese patient: implications for airway management. J Clin Anesth 2001; 13: 144-56.

43 Chung F, Crago RR. Sleep apnoea syndrome and anaesthesia. Can Anaesth Soc J 1982; 29: 439-45.

44 Entwistle MD, Roe PG, Sapsford DJ, Berrisford RG, Jones JG. Patterns of oxygenation after thoracotomy. $\mathrm{Br}$ J Anaesth 1991; 67: 704-11.

45 Knudson J. Duration of hypoxaemia after uncomplicated upper abdominal and thoraco-abdominal operations. Anaesthesia 1970; 25: 372-7.

46 Burgess LP, Derderian SS, Morin GV, Gonzalez C, Zajtchuk JT. Postoperative risk following uvulopalatopharyngoplasty for obstructive sleep apnea. Otolaryngol Head Neck Surg 1992; 106: 81-6.

47 McColley SA, April MM, Carroll JL, Naclerio RM, Loughlin GM. Respiratory compromise after adenotonsillectomy in children with obstructive sleep apnea. Arch Otolaryngol Head Neck Surg 1992; 118: 940-3.

48 Loadsman JA, Hillman DR. Anesthesia and sleep apnea. Br J Anaesth 2001; 86: 254-66.

49 Hanning CD. Obstructive sleep apnea. Br J Anaesth 1989; 63: 477-88. 